


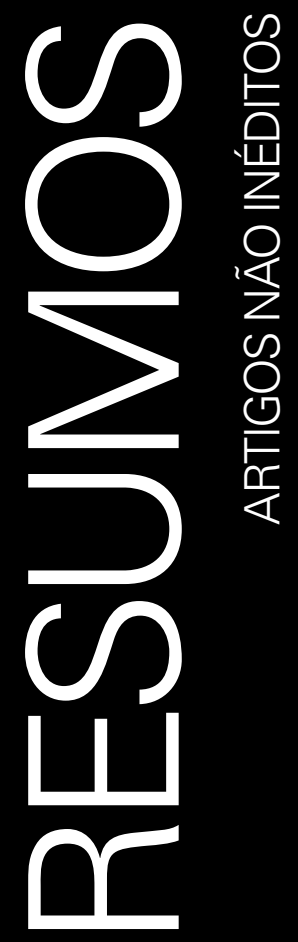





\title{
MATERIALIDADE NO PROJETO DE ARQUITETURA ${ }^{1}$
}

\author{
MATERIALITY IN ARCHITECTURE DESIGN
}

Margarete Maria de Araújo Silva²

Mário Lúcio Pereira Júnior ${ }^{3}$

Roberto Eustaáquio dos Santos ${ }^{4}$

\section{Resumo}

O artigo descreve e apresenta as conclusões da pesquisa "Detalhamento construtivo de alvenarias com utilização de modelagem tridimensional informatizada". Discute o conceito de projeto no processo de produção de edifícios e sua contribuição como instrumento definidor da qualidade final do objeto construído. Além disso, propõe a incorporação da modelagem tridimensional informatizada para o aprimoramento do processo de desenvolvimento de projetos.

Palavras-chave: Alvenaria; CAD; Componentes de alvenaria; Detalhamento construtivo; Metodologia de projeto; Modelagem tridimensional informatizada; Projeto de alvenaria; Projeto para produção.

\begin{abstract}
The article describes and presents the conclusions from the research "Masonry detailing by computer 3D models". It discusses the design concepts in building process and its contributions as a defining instrument towards the quality of the built object. It also proposes computerized 3D model as a feature to improve masonry design process.
\end{abstract}

Keywords: Masonry; CAD; Masonry components; Detailing; Design methodology; 3D modeling; Masonry design detailing; Production design. 